Cell Research(1995),5,155-164

\title{
Studies on the mitotic chromosome scaffold of Allium sativum
}

\author{
ZHAO JiAn ${ }^{1}$, Shaовo JIN, Miao XING, Shui HAO ${ }^{2}$ \\ Institute of Genetics and Cytology, Northeast Normal Uni- \\ versity, Changchun 130024, China.
}

\section{ABSTRACT}

An argentophilic structure is present in the metaphase chromosomes of garlic (Allium sativum). Cytochemical studies indicate that the main component of the structure is non-histone proteins (NHPs). The results of light and electron microscopic observations reveal that the chromosme NHP scaffold is a network which is composed of fibres and granules and distributed throughout the chromosomes. In the NHP network, there are many condensed regions that are connected by relatively looser regions. The distribution of the condensed regions varies in individual chromosomes. In some of the chromosomes the condensed regions are longitudinally situated in the central part of a chromatid while in others these regions appear as coillike transverse bands. At early metaphase, scaffolds of the sister chromatids of a chromosome are linked to each other in the centromeric region, meanwhile, they are connected by scafold materials along the whole length of the chromosome. At late metaphase, however, the connective scaffold materials between the two sister chromatids disappear gradually and the chromatids begin to separate from one another at their ends, but the chromatids are linked together in the centromeric region until anaphase. This connection seems to be related to the special structure of the NHP scaffold formed in the centromeric region. The morphological features and dynamic changes of the chromosome scaffold are discussed.

1. Present Address: Institute of Hematology, Harbin First Hospital, Harbin 150010, China.

2. Corresponding author. 
Key words: Chromosome, nonhistone, scaffold, Allium, sativum.

\section{INTRODUCTION}

Apart from DNA and histones, eukaryotic metaphase chromosomes also contain a large quantity of non-histone proteins (NHPs) [1, 2]. The NHPs have been demonstrated in recent years with a variety of experimental methods to constitute in the chromosomes a scattold or core-like structure[3-16]. In the late 70's, some authors indicated that the residual scaffold in human chromosomes depleted of histones and most NHPs was a loose, fibrillar network [5, 17]. Other authors found that a core-like structure composed of NHPs existed in chromosomes when examined wiht light microscope [6, 7, 18-20], but the structure appeared as a dense, fibrillar network when electron microscopic observations were made on it[15]. The composition of NHPs of the chromosome scaffold has been analyzed biochemically[4, 9, 21], and results of several types of experiments have indicated that topoisomeraseII (Topo II) is one of the main components of the NHPs[12,13]. The distribution and functions of Topo II in chromosomes have also been explored[12-14, 22, 23].

The chromosome scaffold observed by some authors [5, 17] consists only of part of the scaffold NHPs as the major part of the NHPs is depleted during preparation for electron microscopy[3], therefore, the overall morphology of the NHPs in chromosomes remains unclear. Furthermore, the morphology of the chromosome NHPs scaffold has been revealed to be very susceptible to the preparing conditions[17, 2426]. Previous studies of the scaffold structure are carried out mainly with human and animal chromosomes. So far investigations on the scaffold structrue of plant chromosomes have been scarce[25, 27].

By using a technique developed in researches on grasshopper chromosome scaffold[15], we studied the scaffold of garlic mitotic chromosomes. The results are presented in this paper.

\section{MATERIALS AND METHODS}

The materials used in the present study were root tip meristems of garilc (Allium sativum).

\section{Preparation of slides for light microscopy}

Root tip meristems were collected, when the roots reached 1.0 to $1.5 \mathrm{~cm}$ long, from the garlic cloves grown in damp Petri dishes at $25 \pm 2{ }^{\circ} \mathrm{C}$. They were then treated in a solution of saturated bromonaphthalene, or in a solution of $0.002 M$ 8-hydroxyquinoline and $0.05 \%$ colchicine, for 5 to $6 \mathrm{~h}$ at $25^{\circ} \mathrm{C}$. The specimens were washed thoroughly in distilled water and digested in a mixture of 
cellulase and pectinase $(2.5 \%, 1: 1)$ for 4 to $5 \mathrm{~h}$ at $25^{\circ} \mathrm{C}$. Afterwards, the specimens were fixed in a mixture of methanol and acetic acid $(3: 1 \mathrm{~V} / \mathrm{V})$ for $30 \mathrm{~min}$, and chromosome smears were made conventionally. The slides were then rinsed in distilled water, incubated in $2 \times \mathrm{SSC}$ solution $(0.3 \mathrm{M}$ $\mathrm{NaCl}$ and $0.03 \mathrm{M}$ sodium citrate) for $60 \mathrm{~min}$ at $60{ }^{\circ} \mathrm{C}$, rinsed in distilled water again, air dried and stained with silver nitrate $\left(\mathrm{AgNO}_{3}\right)$ according to the procedure proposed by Howell and Black[28]. The slides were observed and photograghed in light microscope.

\section{Cytochemical treatments}

Before the incubation in $2 \times \mathrm{SSC}$, some of the slides were treated, respectively, in the following ways (see Tab 1). 1. They were incubated in a solution of $0.2 \mathrm{~N} \mathrm{H}_{2} \mathrm{SO}_{4}$ at $21{ }^{\circ} \mathrm{C}$ for 60 to 120 $\mathrm{min}$ to remove histones from the chromosomes. 2. They were incubated in a solution of $0.1 \mathrm{~N}$ $\mathrm{NaOH}$ at $21{ }^{\circ} \mathrm{C}$ for 5 to $20 \mathrm{~min}$ to remove NHPs from the chromosomes. 3. They were digested in a solution of $100 \mu \mathrm{g} / \mathrm{ml}$ DNase (Sigma) and $1 \mathrm{mM} \mathrm{MgCl} 2$ in $10 \mathrm{mM}$ Tris-HCl buffer (with the $\mathrm{pH}$ adjusted to 7.1) at $37{ }^{\circ} \mathrm{C}$ for 60 to $120 \mathrm{~min}$. 4. They were digested in a solution of 100 $\mu \mathrm{g} / \mathrm{ml}$ RNase (Sigma) in $0.1 \mathrm{M}$ acetate buffer (pH 7.5) at $37^{\circ} \mathrm{C}$ for 60 to $120 \mathrm{~min}$. 5. they were treated in a solution of $100 \mu \mathrm{g} / \mathrm{ml}$ trypsin (Sigma) in $0.85 \% \mathrm{NaCl}$ at $37{ }^{\circ} \mathrm{C}$ for 5 to $20 \mathrm{~min}$. After the cytochemical treatments mentioned above, the slides were rinsed in distilled water, incubated in $2 \times$ SSC, stained with AgNO3 as described above, observed and photograghed in light microscope.

\section{Preparation of samples for transmission electron microscopy}

Samples for electron microscopy were prepared according to the procedure previously reported[15] Briefly, the suitable silver-stained slide preparations were selected by light microscopy, and then transferred from the slides onto grids, observed and photograghed with an Hitachi-600 transmission electron microscope.

\section{RESULTS}

Morphology and cytochemical features of garlic chromosome scaffold revealed by light microscopy

An argentophilic network-like structure is observed with light microscope in silverstained mitotic chromosomes of garlic (Fig 1). The structure is distributed throughout the chromosome and retains the basic morphology of a metaphase chromosome. It is composed of two juxtaposed chromatid-like argentophilic components which seem to be linked to each other by argentophilic materials. Careful observations reveal that the argentophilic component in some regions of a chromatid seems to be helically coiled (Figs lc and d, arrows).

In order to demonstrate the chemical nature of the argentophilic structure, we treated the chromosome preparations with different enzymes and chemicals and then stained the preparations with silver nitrate. Our results revealed that the argentophilic structure appears normally after treatment of DNase (Fig 2a) and RNase (Fig $2 \mathrm{~b}$ ), but it is destroyed by trypsin so seriously that argentophilic materials remained only in the periphery of trypsin-treated, silver-stained chromosomes (Fig 2c) indicating that the main component of the argentophilic structure is proteins. The perichromosomal layer is heterogeneus in composition and the proteins in this part deffer from that of inside the chromosome[29, 30]. We suppose the argentophilic materials remaind in the periphery of trypsin treated chromosome in this study 


\section{Chromosome scaffold of Allium sativum}

may represent proteins of the perichromosomal layer which are more stable to the trypsin digestion. Furthermore, the argentophilic structure remains after the treatment of $0.2 \mathrm{~N} \mathrm{H} 2 \mathrm{~S} 04$ (Fig 2d), but it disappears completely after treatment of $0.1 \mathrm{~N}$ $\mathrm{NaOH}$ (data not shown), demonstrating that the structure is composed principally of NHPs[6].

The effects of different treatments upon the garlic chromosome scaffold are summerized in Tab 1.

Tab 1. Effects of different treatments upon garlic chromosome scaffold

\begin{tabular}{llcccc}
\hline Treatnmnt & $\begin{array}{l}\text { Concent. of } \\
\text { enzymes or } \\
\text { chemicals }\end{array}$ & $\begin{array}{c}\text { Temp. of } \\
\text { treatment }\end{array}$ & $\begin{array}{c}\text { Time of } \\
\text { treatment } \\
\text { (min) }\end{array}$ & $\begin{array}{l}\text { Optimal time } \\
\text { for silver } \\
\text { staining(min) }\end{array}$ & Results \\
\hline DNase & $100 \mu \mathrm{g} / \mathrm{ml}$ & $37^{\circ} \mathrm{C}$ & $60-120$ & $3-5$ & + \\
RNase & $100 \mu \mathrm{g} / \mathrm{ml}$ & $37^{\circ} \mathrm{C}$ & $60-120$ & $10-15$ & + \\
Trypsin & $100 \mu \mathrm{g} / \mathrm{ml}$ & $37^{\circ} \mathrm{C}$ & $5-20$ & $10-18$ & - \\
$\mathrm{H}_{2} \mathrm{SO}_{4}$ & $0.2 \mathrm{~N}$ & $21^{\circ} \mathrm{C}$ & $60-120$ & $10-15$ & + \\
$\mathrm{NaOH}$ & $0.1 \mathrm{~N}$ & $21^{\circ} \mathrm{C}$ & $5-20$ & $10-18$ & - \\
\hline
\end{tabular}

+: The scaffold is not affected.

- : The scaffold is destroyed or disappeared
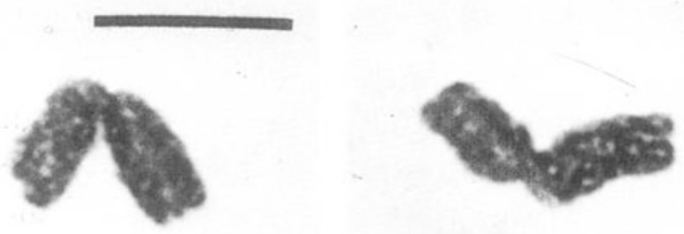

\section{a}

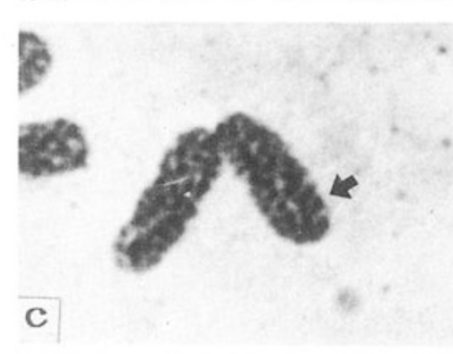

b

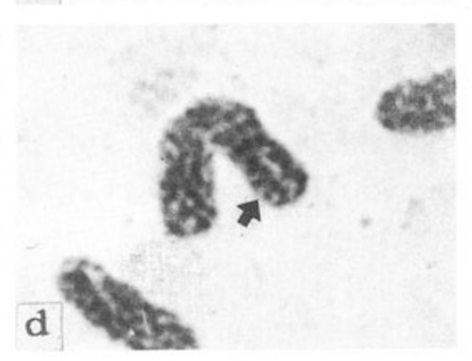

Fig 1. Light microscopic structure of silver-stained scaffolds of garlic mitotic chromosomes. The scaffold appears as a network-like structure distributed throughout the chromosomes. The scaffold seems to be helically coiled in some regions (arrows). Bar represents $10 \mu \mathrm{m}$. 


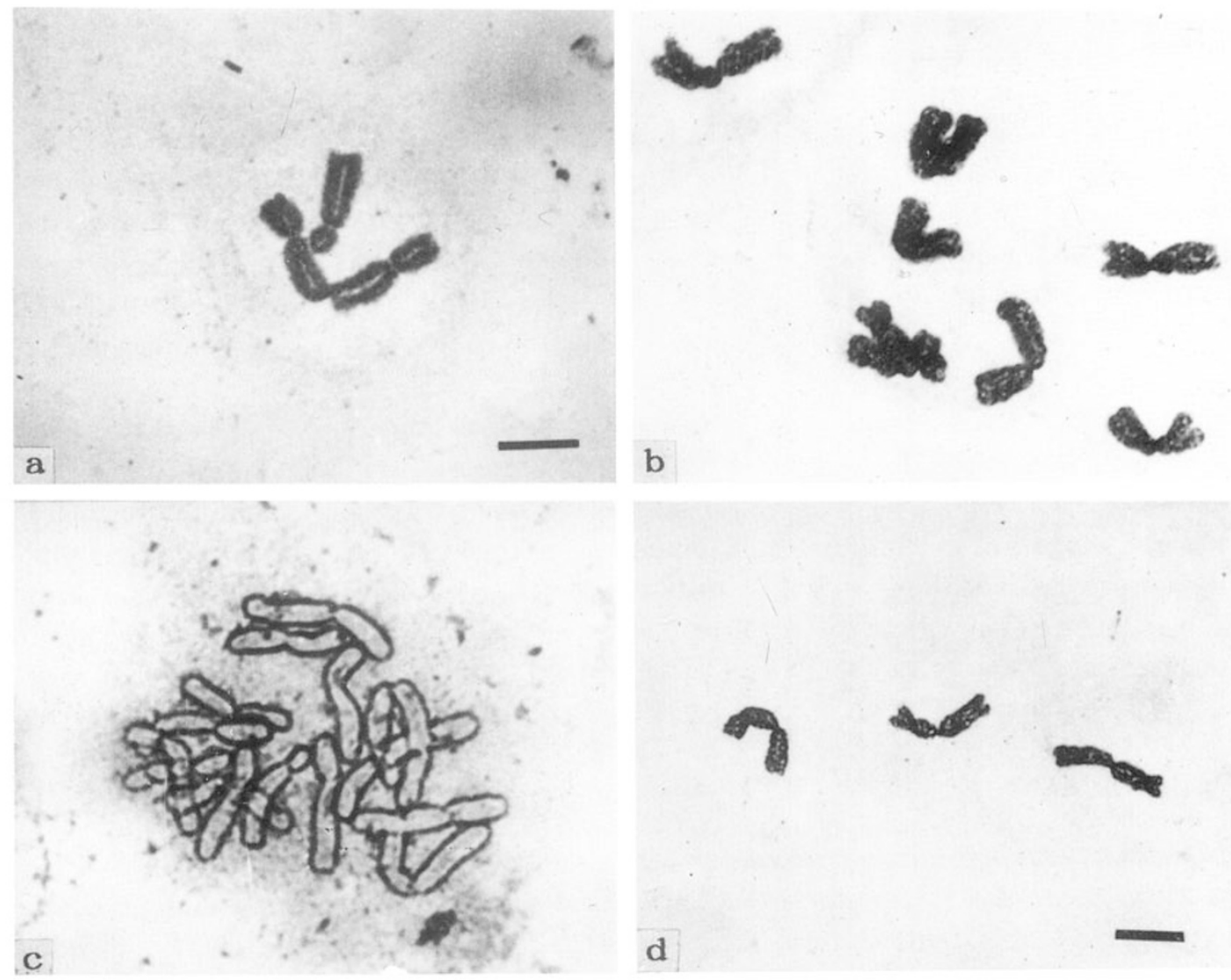

Fig 2. Silver-stained scaffolds of garlic chromosomes after (a) digestion of DNase; (b) digestion of RNase; (c) digestion of trypsin; (d) treatment of $0.2 \mathrm{~N} \mathrm{H}_{2} \mathrm{SO}_{4}$. The chromosome scaffold is not affected by the treatments of DNase, RNase or $0.2 \mathrm{~N} \mathrm{H}_{2} \mathrm{SO}_{4}$, but it is destroyed seriouly by trypsin. Magnifications of $a, b$ and $c$ are same. Bars represent $10 \mu \mathrm{m}$.

Fine structure of garlic metaphase chromosome scaffold revealed by electron microscope

Fig $3 a_{1}$ and $3 b_{1}$ show the silver-stained scaffolds of garlic metaphase chromosomes observed with light microscope. To examine further the fine structure of the scaffolds, we transferred the chromosome preparations from slides onto grids and made electron microscopic observations on them. The scaffold viewed in electron microscope appear as a network-like structure which is composed of fibres and granules, distributed throughout the chromosome, and retains the basic morphology of the chromosome (Figs $3 \mathrm{a}$ and $3 \mathrm{~b}$ ). At early metaphase, scaffolds of the sister chromatids of a chromosome are linked together in the centromeric region and connected with each other by scaffold materials in other regions (Fig 3a). At late metaphase, 

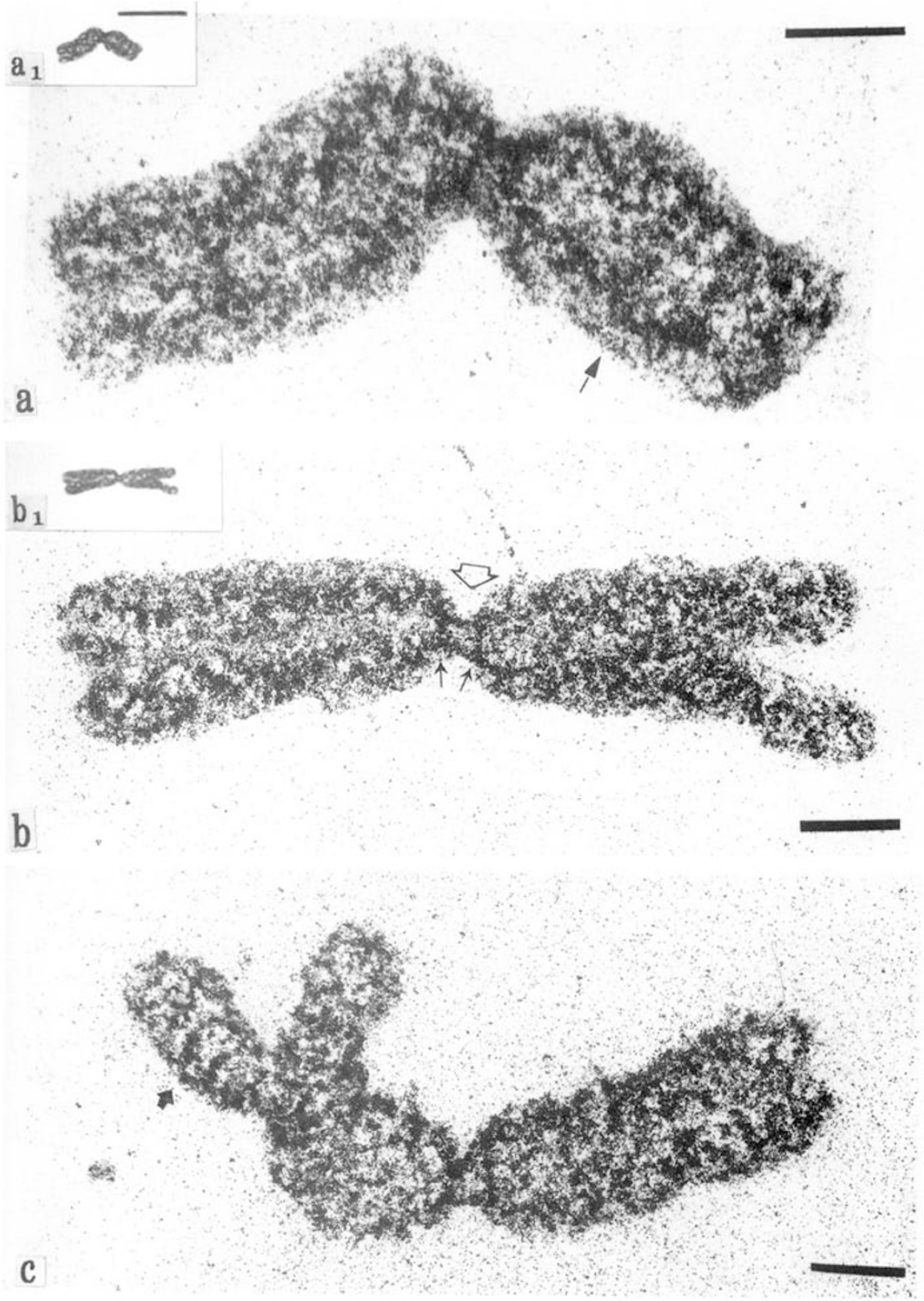

Fig 3. a, b and c show the silver-stained NHP scaffold of garlic metaphase chromosomes observed with electron microscope. The same chromosomes as shown in a and b were firstly observed with light microscope $\left(a_{1}\right.$ and $\left.b_{1}\right)$. In early metaphase the scaffolds of the sister chromatids are connected along the entire length of the chromosome (a). At late metaphase the connective scaffold materials between the two sister chromatid scaffolds disappear gradually and the sister chromatids begin to separate from each other at the ends ( $b$ and c), but the scaffolds of the sister chromatids are linked together in the centromeric region. Bars in $\mathrm{a}, \mathrm{b}$ and $\mathrm{c}$ represent $2 \mu \mathrm{m}$. Bars in $\mathrm{a}_{1}$ and $\mathrm{b}_{1}$ represent $10 / \mu \mathrm{m}$. 
the connective scaffold materials between the two sister chromatids disappear gradually, meanwhile, the sister chromatids begin to separate from each other at their ends (Figs $3 \mathrm{~b}$ and $3 \mathrm{c}$ ). The NHP materials are not distributed uniformly in the scaffold, they are condensed in some regions and formed relatively more compact structures. In some cases, the structures are longitudinally situated in the central part of a chromatid (Fig 3a, arrow) while in other cases they take the shape of coil-like transverse bands (Figs 1c, $1 \mathrm{~d}$ and 3c, arrows). It seems that the chromosome scaffold is a dynamic structure which may take different shapes in different chromosomes.

In the centromeric region scaffold NHPs are highly condensed and special structures are formed. The two arms of the scaffold of a chromatid are connected by a longitudinal, highly electron- dense fibrillar component (Fig 3b, open arrow). Meanwhile, two transverse highly electron- dense fibrillar components are present in the centromeric region to link the sister chromatids together (Fig 3b, thin arrow). It is suggested that the special structures of scaffold NHPs in the centromeric region may play an important role in maintaining the two sister chromatids of a metaphase chromosome.

\section{DISCUSSION}

Paulson and Laemmli observed in electron microscope the residual scaffold of HeLa metaphase chromosomes and found that the scaffold was a loose network of fibres[5]. With a similar method, Hadlaczky et al. studied the residual scaffolds of animal (Chinese hamster) and plant (wheat and opium poppy) chromosomes, and they suggested that the scaffold was not a continuous proteineous network; it is was a structure composed of discontinuous proteineous particles which were connected by connective DNA fibres[24, 27]. Earnshaw and Laemmli investigated the residual scaffold of chromosomes, and pointed out that the scaffold was a fibrillar network distributed throughout the chromosome, rather than a rod-like structure only along the central axis of the chromosome, and that the morphology of the scaffold was related to the changes of the cellular enviorenment, especially to the concentration of $\mathrm{Mg}^{2+}[9]$. Paulson re-examined by electron microscopy the scaffold of histonedepleted Hela metaphase chromosomes and he emphasized that the scaffold was an interconnected fibrillar network in which no prominent longitudinal fibres were present[17]. It is clear that the opinions of these researchers about the morphology of the chromosome scaffold are divergent. The methods used by the above authors in their study of the chromosome scaffold involved removing histones (and most NHPs) from chromosomes, spreading the isolated, histone-depleted chromosomes and observing with electron microscope, but investigators have indicated that many factors in the preparations of the samples (such as cation concentration, ionic strength and surface tension, etc.) have direct influence on the morphology of the chromosome 
scaffold[4, 9, 21, 24, 31]. Therefore, the reality of the chromosome scaffold has been questioned by some authors[27, 31].

By using hypotonic pretreatment, silver staining and light microscopy, Howell and Hsu first reported the existence of an argentophilic core (scaffold) in the intact chromosomes[6]. Nevertheless, the resolution of light microscope does not allow the demonstration of the fine structure of the core. Recently, with a newly developed squash-whole mount-silver staining electron microscope technique, we studied the mitotic chromosome scaffold of grasshopper and proved that the core (scaffold) revealed by light microscopy is comprised of a compact network of fibres[15]. In this paper, NHP scaffold of garlic chromosomes was studied with a method similar to the technique reported previously[15]. The results indicated that NHPs constitute a compact network (i.e. the NHP scaffold), there are many condensed regions which are connected by relatively loose regions. The distribution of the condensed regions varies in individual chromosomes. In some of the chromosomes, the condensed regions are longitudinally situated in the central part of each chromatids (Fig 3a, arrow), while in others the condensed regions appear as coil-like transverse bands (Figs lc, d and 3c,arrow). We suggest that the NHP scaffold in vivo undergoes dynamic changes which result in the variations mentioned above.

Homberger and Koller (1988) pointed out that specific nonhistone components, independent of histone-DNA interactions, organize the structure of metaphase chromosomes[32]. The results of our recent study make clear that during the process of prophase the configuration of the NHPs gradually showed the morphology of chromosomes. We suggest, therefore, that the construction of prophase chromosomes is related to the dynamic changes in NHPs[33]. Moreover, as mentioned above, Earnshaw and Laemmli based on their experments concluded that the morphology of the scaffold was related to the changes of cellular environment, especially to the concentration of $\mathrm{Mg}^{2+}$ [9]. The results of all these investigations indicated that the chromosome NHP scaffold is a dynamic structure which is correlated with the morpholical changes of the chromosome.

Based on the results of previous studies and the present paper, we suggest the follwing points:

1. The NHP scaffold is a compact, fibrillar network distributed throughout the chromosomes[15, 16]

2. The scaffold materials are unevenly distributed in the network and so many condensed regions, especially the special structures in the centromeric region, are formed (results in this paper).

3. The morphology and distribution of the NHP scaffold vary under different conditions. In some instances, condensed regions are located along the central axis of the chromosome while in others they appear as helical coils[6, 7, 14, 15, 18 and the results in this paper], suggesting that the scaffold is a dynamic structure.

4. At early metaphase, the scaffolds in two sister chromatids of a chromosome are interconnected not only in the centromeric region but also along the entire length 
of the chromosome (Fig 3a). At late metaphase, this interconnection disappears gradually and the two sister chromatids are separated each other from their ends. This phenomenon suggests that the dynamic changes of the NHP scaffold have a direct bearing on the maintenance and separation of the sister chromatids.

\section{REFERENCES}

[1] Bostock C J, Sumner AT. The Eukaryotic chromosome. Elsevier /North-Holland Biomedical press, Amsterdam 1978.

[2] Holde KE van, Chromatin. Springer, New York, Heidelberg, Berlin, 1989; pp181-218.

[3] Adolph KW, Cheng SM, Laemmli UK. Role of non-histone proteins in metaphse chromosome structure, Cell 1977; 12:805-16.

[4] Adolph KW, Cheng SM, Paulson JR, Laemmli UK. Isolation of a protein sacffold from mitotic HeLa cell chromosomes. Proc Natl Acad Sci USA 1977; 74:4937-41.

[5] Paulson JR, Laemmli UK. The structure of histone-depleted metaphase chromosomes. Cell $1977 ; 12: 817-28$.

[6] Howell WM, Hsu TC. Chromosome core structure revealed by silver staining. Chromosoma 1979; 73:61-6.

[7] Satya-Prakash KL, Hsu TC, Pathak S. Behaviour of chromosome core in mitosis and meiosis. Chromosoma 1980; 81:1-8.

[8] Rufas JS, Gimenez-Martin G, Esponda P. Presence of a chromatid core in mitotic and meiotic chromosomes of grasshopper. Cell Biol Intl Rep 1982; 6:261-7.

[9] Earnshaw WC, Laemmli UK. Architecture of metaphase chromosomes and chromosome scaffolds. J Cell Biol 1983; 96:84-93.

[10]Earnshaw WC, Laemmli UK. Silver staining the chromosome scaffold. Chromosoma 1984; 89:186-92.

[11]Sentis C, Rodriguez-Campos A, Slokert JC, Fermandez-Pigueras J. Morphology of the axial structure in the neo-XY sex bivalent of Pycnogaster cucullata (Orthoptera) by silver impregnation. Chromosoma 1984; 90:317-21.

[12]Earnshaw WC, Heck MMS. Localization of topoisomerase II in mitotic chromosomes. J Cell Biol 1985; 100:1716-25.

[13]Gasser SM, Laroche T, Falquet J, Boy de la Tour, Laemmli UK. Metaphase chromosome structure: Involvement of topoisomerase II. J Mol Biol 1985: 188:613-29.

[14]Boy de la Tour, Laemmli UK. The metaphase scaffold is helically folded: Sister chromatids have predominantly opposite helical handedness. Cell 1988; 55:937-44.

[15]Zhao J, Hao S, Xing M. The fine structure of the mitotic chromosome core (scaffold) of Trilophidia annulata. Chromosoma 1991; 100:323-9.

[16]Cai S, Zeng C, Li J, Zhai Z. Identification of the nuclear matrix and chromosome scaffold in dinoflagellate Crypthecodinium cohnii. Cell Res 1992; 2:165-82.

[17]Paulson JR. Scaffold morphology in histone-depleted HeLa metaphase chromosomes, Chromosoma 1989; 97:289-95.

[18]Nokkala S, Nokkala C. Coiled internal structure of chromonema within chromosomes suggesting hierarchical coil model for chromosome structure. Hereditas 1986; 104:29-40.

[19]Zhao J, He MY, Hao S. Spiral structure and chromosome core in meiotic chromosomes of grasshopper. Acta Biol Exp Sinica 1990; 23:261-71.

[20]Zhao J, He MY, Hao S. Formation of chromatid cores and synaptonemal complexes in meiotic chromosomes of Angaracris rhodapa. Chinese J Genet 1992; 19:13-9.

[21]Lewis CD, Laemmli UK: Higher order metaphase' chromosome structure: Evidence for metalloprotein interactions. Cell 1982; 29:171-81. 


\section{Chromosome scaffold of Allium sativum}

[22] Adachi Y, Luke M, Laemmli UK. Chromosome assembly in vitro: Topoisomerase II is required for condensation. Cell 1991; 64:137-48.

[23] Hirano T, Mitchison TJ. Topoisomerase II does not play a scaffolding role in the organization of mitotic chromosomes assembled in Xenopus egg extracts. J Cell Biol 1993; 120:601-12.

[24] Hadlaczky G, Sumner AT, Ross A. Protein-depleted chromosomes. I. Structure of isolated protein-depleted chromosomes. Chromosoma 1981; 81:537-55.

[25] Hadlaczky G. Structure of metaphase chromosomes of plants. Intl Rev Cytol 1985; 94:57-75.

[26] Earnshaw WC, Heck MMS. The ultrastructure of the mitotic chromosomes scaffold: Studies using whole mount electron midroscopy and immunocytochemical techniques. In: Adolph KW (ed) Chromosome and chromatin. Vol 3, CRC Press, Boca Raton, Flo 1988; pp37-56.

[27] Hadlaczky G, Sumner AT, Ross A, Protein-depleted chromosomes. II. Experiments concerning the reality of chromosome scaffolds. Chromosoma 1981; 81:557-67.

[28] Howell WM, Black DA, Controlled silver staining of nucleolar organizer regions with a protective colloidal developer: a 1- step method. Experientia 1980; 36:1014-5.

[29] Xing M, Hao S, Hu A. Electron microscopic observations on the behaviour of perichromosomal RNP from prophase to metaphase in Vicia faba. Acta Biol Exp Sinica 1989; 22:367-75.

[30] Hernandez-Verdun D, Gautier T. The chromosome periphery during mitosis. Bio Essays 1994; 16:179-85.

[31] Comings DE, Okada TA. Chromosome scaffolding structure Real or artifact? J Cell Biol 1979; 83 (2, Part 2):150a

[32] Homberger H, Koller T. The integrity of the histone-DNA complex in chromatin fibres is not necessary for the maintenance of the shape of mitotic chromosomes. Chromosoma 1988; 96:197204.

[33] Hao S, Jiao MD, Zhao J, Xing M, Huang BC. Reorganization and condensation of chromatin in mitotic prophase nuclei of Allium cepa. Chromosoma 1994; 103:432-40.

Received 1-11-1994. Revised 27-2-1995. Accepted 25-7-1995 